Published in final edited form as:

Hepatology. 2013 April ; 57(4): 1654-1662. doi:10.1002/hep.26115.

\title{
Natural Killer Cells in Liver Disease
}

\author{
Zhigang Tian ${ }^{1}$, Yongyan Chen ${ }^{1}$, and Bin Gao ${ }^{2}$ \\ ${ }^{1}$ Department of Microbiology and Immunology, School of Life Sciences, University of Science and \\ Technology of China, Hefei, Anhui 230027, China \\ ${ }^{2}$ Laboratory of Liver Diseases, National Institute on Alcohol Abuse and Alcoholism, National \\ Institutes of Health, Bethesda, MD 20892, USA
}

\begin{abstract}
Natural killer (NK) cells are enriched in lymphocytes within the liver and have unique phenotypic features and functional properties, including TRAIL-dependent cytotoxicity and specific cytokine profiles. As a key component of innate immunity in the liver, NK cells perform critical roles in host defense against pathogens and tumors via their natural cytotoxicity and cytokine production, and they also act as regulatory cells by engaging in reciprocal interactions with other types of liver cells through cell-to-cell contact and the production of cytokines. Accumulating evidence from the last decade suggests that NK cells play an important role in controlling viral hepatitis, liver fibrosis, and liver tumorigenesis but also contribute to the pathogenesis of liver injury and inflammation. The characterization of intrahepatic NK cell functions has not only helped us to better understand the pathogenesis of liver disease but has also revealed new therapeutic targets for managing this disease.
\end{abstract}

\section{Keywords}

viral hepatitis; liver fibrosis; liver tumor; cytokine; NKG2D

Natural killer (NK) cells were functionally identified in 1975 as a unique subset of lymphocytes based on the presence of distinctive cytoplasmic granules. Currently, the understanding of NK cell biology and function is much clearer. Consistent with their roles in immune defense and surveillance, NK cells are widely distributed in the body throughout lymphoid and non-lymphoid tissues. The tissue with the highest frequency of NK cells among its lymphocytes is the lung, followed by the liver, the peripheral blood, the spleen, the bone marrow, the lymph nodes, and the thymus. Accumulating evidence suggests that NK cell functions are strongly influenced by the tissue microenvironment. In particular, NK cells within a healthy liver exhibit a higher level of cytotoxicity against tumor cells and express higher levels of cytotoxicity mediators when compared with peripheral NK cells. ${ }^{1},{ }^{2}$ Healthy liver NK cells can be further activated during chronic hepatitis (HCV) virus infection or by IFN-a antiviral therapy, ${ }^{3}-5$ playing critical roles in controlling viral hepatitis ${ }^{3-5}$ and liver fibrogenesis, ${ }^{5}-10$ although a recent study suggests that intrahepatic NK cell cytotoxic function is impaired in chronic HCV infection. ${ }^{11}$ In addition, chronic alcohol consumption is associated with the suppression of liver NK cell functions, which contributes to the pathogenesis of alcoholic liver disease. ${ }^{12}$ In this review, we highlight recent advances in the understanding of NK cell functions in the anti-viral, anti-fibrotic, and anti-tumor

Address correspondence and reprint requests to Zhigang Tian, M.D., Ph.D., School of Life Sciences, University of Science and Technology of China, Hefei 230027, China, tzg@ustc.edu.cn or Bin Gao, M.D., Ph.D., Laboratory of Liver Diseases, National Institute on Alcohol Abuse and Alcoholism, National Institutes of Health, Bethesda, MD 20892, USA, bgao@ mail.nih.gov. 
responses in the liver and briefly discuss the potential of NK cells as therapeutic targets for the treatment of liver disease.

\section{Hepatic NK cells}

NK cells are enriched in the liver, accounting for $25-40 \%$ and $10-20 \%$ of the total intrahepatic lymphocytes in human and mouse livers, respectively. Liver NK cells, which were originally described as "pit cells," show different immunophenotypical, morphological, and functional characteristics from peripheral NK cells. The mechanisms underlying the enrichment and special characteristics of liver NK cells remain largely unknown; however, these effects may be related to both the high hepatic expression levels of several NK cellrecruiting chemokines ${ }^{13}$ and the crosstalk between NK cells and other liver cell types. ${ }^{14}$

Human NK cells express specific markers, which are summarized in Figure 1. A description of liver NK cells in mice has been previously reviewed ${ }^{15}$ and is not discussed in the present review. Human NK cells are defined as $\mathrm{CD}^{+} 6^{+} \mathrm{CD} 3^{-}$lymphocytes and can be grouped as CD56 $6^{\text {bright }}$ and CD56 ${ }^{\text {dim }}$ subsets based on the levels of CD56 expression. Approximately $90 \%$ of peripheral blood and spleen NK cells are CD56 $6^{\mathrm{dim}}$; whereas only $50 \%$ of liver NK cells are CD56 ${ }^{\text {dim }}$ and other $50 \%$ of them are CD56 $6^{\text {bright }}$. The CD56 $6^{\text {bright }}$ and CD56 ${ }^{\text {dim }} \mathrm{NK}$ cell subsets differ in their proliferative responses to IL-2, intrinsic cytotoxic capacity, cytokine production, NKR repertoire, and adhesion molecule expression (Figure 1).

The studies from human liver transplantation suggest that circulating NK cell precursors (most probably derived from the bone marrow) migrate into the liver and subsequently differentiate into liver-specific NK cells, a population of cells that have many different characteristics and functions from circulating NK cells (Table I). For example, compared with peripheral NK cells, liver NK cells display a higher level of killing activity, express higher levels of cytotoxic mediators, ${ }^{1},{ }^{2}$ and show a significantly higher level of CD69 expression, which is an acute activation marker that is expressed transiently on recently activated lymphocytes. ${ }^{16}$

The functions of NK cells are to kill target cells and produce a variety of cytokines, such as IFN- $\gamma$. The ability of NK cells to kill target cells is determined by the opposing signals from the inhibitory and stimulatory receptors on the NK cells and their interactions with the corresponding ligands expressed on the target cells. ${ }^{26},{ }^{27}$ The NK cell inhibitory receptors (e.g., CD94/NKG2, Ly49A) interact with the inhibitory ligands (e.g., MHC class I molecules) that are expressed on the target cells to suppress NK cell function. The stimulatory receptors (e.g., NKG2D, NKp46, NKp30, NKp44) interact with the stimulatory ligands that are expressed on the target cell and promote NK cell activity. The expression of these inhibitory and stimulatory receptors on NK cells and their ligands on hepatocytes and nonparenchymal cells are significantly altered during liver disease and contribute to the disease pathogenesis. ${ }^{28}$

\section{Hepatic NK cells and the pathogenesis of liver disease}

As a key component of the innate immune system in the liver, NK cells can directly, or indirectly through the production of cytokines, kill pathogens, tumor cells, and stressed hepatocytes, and hepatic stellate cells (HSCs). NK cells can also act as regulatory cells that influence dendritic cells (DCs), Kupffer/macrophages, T cells, B cells, and endothelial cells by producing various cytokines (including IFN- $\gamma$, TNF-a, and IL-10), chemokines, and growth factors or through innate immune recognition. The details about how NK cells interact with liver cells and immune cells are described below and summarized in Figure. 2. 


\section{The crosstalk between NK cells and other types of immune cells in the liver}

In the liver, many types of immune cells can interact with and subsequently activate NK cells. For example, TLR ligand-activated Kupffer cells can induce NK cell activation via a cell-cell contact mechanism. ${ }^{29}$ Kupffer cell-derived IL-12 plays an important role in the recruitment and activation of hepatic NK cells and contributes to poly I:C-induced mild liver injury, ${ }^{30}$ whereas the combination of Kupffer cell-derived IL-12 and IL-18 contributes to poly I:C/D-galactosamine-induced fulminant hepatitis by enhancing the crosstalk between NK cells and Kupffer cells. ${ }^{31}$ NKT cell-derived IL-4 and IFN- $\gamma$, or the elevated expression of NK cell-activating ligands on hepatocytes, enhance the cytotoxicity of NK cells against hepatocytes, resulting in an increased sensitivity of HBV transgenic mice to immunologic (poly I:C or Con A) or chemical $\left(\mathrm{CCl}_{4}\right)$ challenge. ${ }^{32}$ Moreover, DCs can induce NK cell activation in a mouse model of $\mathrm{HBV}$ infection, which induces a massive degeneration of HBV-infected hepatocytes and fulminant hepatitis via Fas/FasL interactions. ${ }^{33}$ In contrast, T regulatory cells have been shown to suppress NK cell activation and ameliorate neonatal bile duct injury via the production of IL-10 and TGF- $\beta,{ }^{34}$ whereas activated HSCs also produce high levels of TGF- $\beta$, which inhibits the anti-fibrotic functions of NK cells. ${ }^{35}$

In addition to the detrimental functions of liver NK cells, they may also perform protective roles in either suppressing cholestatic liver injury by stimulating Kupffer cell-dependent IL-6 production ${ }^{36}$ or inhibiting T cell hepatitis by inducing T and NKT cell apoptosis. ${ }^{37}$

\section{Innate immune recognition by hepatic NK cell receptors}

The interactions between NK cells and target cells are controlled by the many stimulatory and inhibitory receptors on the NK cells and their corresponding ligands on the target cells. Among these interactions, those between NKG2D and its ligands have been extensively investigated in liver disease pathogenesis. ${ }^{28}$ It has been reported that the expression levels of NKG2D ligands are upregulated in hepatocytes, ${ }^{32},{ }^{38}$ cholangiocytes, ${ }^{39}$ activated HSCs, ${ }^{8}, 10$ and Kupffer cells ${ }^{31}$ in human liver diseases and animal models. These ligands can bind to NKG2D on the NK cells and subsequently activate the NK cells to produce a variety of cytotoxic mediators that not only induce liver injury by killing hepatocytes and cholangiocytes ${ }^{32}, 38,39$ but also inhibit liver fibrosis by killing HSCs. ${ }^{6},{ }^{8}, 10$ The expression of NK cell receptors is also significantly altered during viral hepatitis or after IFN- $a$ antiviral therapy, which plays an important role in controlling viral hepatitis and is discussed in a later section.

\section{The expression of death receptor ligands by hepatic NK cells}

One of the special characteristics of hepatic NK cells is their expression of TRAIL, which is upregulated in patients with viral hepatitis,${ }^{40}$ after IFN-a anti-viral therapy, ${ }^{4},{ }^{41}$ or in IFN$\gamma$-treated mice. ${ }^{8}$ TRAIL-expressing NK cells in the liver contribute to hepatocellular damage, ${ }^{40},{ }^{42} \mathrm{HCV}$ clearance, $,{ }^{4},{ }^{41}$ and the inhibition of liver fibrogenesis. ${ }^{6},{ }^{8}$ Several studies have reported that the expression of TRAIL on peripheral blood NK cells, which is detected at very low levels in normal healthy individuals, is elevated during chronic $\mathrm{HCV} .{ }^{3}$ However, other studies have not found this difference in TRAIL expression on peripheral blood NK cells between healthy controls and patients with HCV or HBV. ${ }^{41}$ In addition to TRAIL, other cytotoxic mediators, such as FAS, perforin, and granzyme, may also be involved in the cytotoxicity of NK cells against hepatocytes ${ }^{43}$ and HSCs. ${ }^{6}, 9$

\section{The activation of hepatic NK cells by cytokines}

In addition to the NK cell-activating ligands, many cytokines can induce NK cell activation in the liver, including IFN- $\alpha / \beta$, IL-2, IL-12, IL-15, IL-18, and IFN- $\gamma$. Among these cytokines, IFN- $\alpha / \beta$ is believed to be the most potent activator of NK cell cytotoxicity, IL-12 
and IL-18 are strong inducers of NK cell production of IFN- $\gamma$, and IL-15 promotes NK cell proliferation. Emerging evidence suggests that the IFN- $\alpha / \beta$ produced by $\mathrm{HCV}$-infected hepatocytes, or treatment with exogenous IFN- $\alpha / \beta$, plays a critical role in inducing NK cell activation and controlling HCV infection..${ }^{4}{ }^{41}$ Moreover, the hepatic expression levels of IL-12, IL-15, and IL-18 are elevated in immune-activated HBV patients and positively correlate with liver NK cell functions and the liver histological activity index. ${ }^{44}$ These data suggest that cytokine-mediated NK cell activation contributes to hepatocellular damage during viral hepatitis. ${ }^{44}$

\section{The suppression of hepatic NK cells by cytokines}

Several cytokines have been shown to inhibit the functions of hepatic NK cells. Among these cytokines, TGF- $\beta$, which is elevated during chronic liver injury, is the most potent inhibitor of liver NK cell-mediated cytotoxicity and cytokine production. The increased level of TGF- $\beta$ may result in the significant inhibition of the anti-viral and anti-fibrogenic effects of NK cells via the downregulation of expression of NKG2D. ${ }^{12},{ }^{35},{ }^{45},{ }^{46} \mathrm{In}$ addition, IL-10 selectively blocks the NK cell secretion of IFN- $\gamma$ but does not affect NK cell cytotoxicity or TRAIL expression, thereby reducing the anti-viral activity of NK cells without altering NK cell-mediated liver injury during a chronic HBV infection. ${ }^{47}$

\section{Cytokine production by NK cells}

In addition to the direct killing of target cells, NK cells can also affect target cells via the production of a variety of cytokines (IFN- $\gamma$ TNF- $\alpha$, IL-10, IL-12, IL-22, etc.) and chemokines (MIP-1, IL-8, RANTES, etc.). Among them, IFN- $\gamma$ is the most prominent cytokine produced by NK cells and contributes to many of the NK cell functions in the liver, such as anti-viral, ${ }^{48}$ anti-fibrotic, ${ }^{8}$ anti-regenerative, ${ }^{49}$ and anti-tumor effects. ${ }^{50}$ However, the contributions of the other cytokines and chemokines produced by NK cells to the pathogenesis of liver disease have not been carefully explored.

\section{NK cells and human liver diseases}

A series of studies in humans and mice has suggested that NK cells are involved in the immunodefense and immunopathology of the liver. These cells play beneficial roles by inhibiting viral infection, tumor cell growth, and liver fibrosis but also play detrimental roles by enhancing hepatocellular damage and inhibiting liver regeneration (Figure 3 ).

\section{HCV}

NK cells have been known to play an important role in the control of viral infection for many years. However, early studies suggested that HCV inhibits NK cell functions and escapes from the immune surveillance of NK cells, leading to chronic infection.

Consequently, the function of NK cells during HCV infection had not received much attention until a recent genetic study showed that patients with a specific combination of the inhibitory receptor KIR2DL3 and its group 1 HLA-C ligand are resistant to chronic HCV infection. ${ }^{51}$ Multiple follow-up genetic and clinical studies have suggested that NK cells not only play an important role in both spontaneous and IFN- $\alpha$ therapy-based HCV clearance but may also contribute to hepatocellular damage in viral hepatitis (see reviews ${ }^{52},{ }^{53}$ ).

During acute HCV infection, NK cells are activated by IFN- $\alpha / \beta$ and other cytokines, such as IL-12, IL-15, IL-18. ${ }^{54}$ These activated NK cells may play important roles in controlling/ preventing $\mathrm{HCV}$ infection by killing $\mathrm{HCV}$-infected hepatocytes or priming adaptive immunity. 55,56 
The roles of peripheral NK cells and the effects of IFN-a antiviral therapy on these cells during chronic HCV infections have been extensively investigated in the last decade by many groups (see reviews ${ }^{52}, 53$ and the references therein). Many studies ${ }^{3},{ }^{5},{ }^{56}{ }_{-} 59$ support the finding that peripheral NK cells are activated during a chronic $\mathrm{HCV}$ infection, most likely via IFN- $\alpha / \beta$ signaling. These activated peripheral NK cells display an increase in cytotoxicity, with elevated expression of NKG2D, NKp46, and TRAIL and elevated activation of STAT1, along with a decrease in IFN- $\gamma$ production. The elevated cytotoxicity level of NK cells may contribute to liver injury, whereas the decreased production of IFN- $\gamma$ may facilitate the inability to clear $\mathrm{HCV} .{ }^{3},{ }^{57} \mathrm{IFN}-\mathrm{a}$ treatment rapidly induces the activation of peripheral NK cells in patients with chronic HCV infection, which is indicated by increases in STAT1 activation, cytotoxicity, and TRAIL expression, and plays an important role in controlling HCV replication. ${ }^{4},{ }^{41}, 59$

In contrast, studies on the functions of intrahepatic NK cells in HCV pathogenesis have been limited due to the inherent limitations of liver biopsies and a lack of the appropriate control liver samples. Several studies ${ }^{3}{ }^{5}$ have shown that intrahepatic NK cells have significantly higher levels of TRAIL, NKp46, and CD122 expression and cytotoxicity than peripheral blood NK cells of HCV patients; these levels are further increased after IFN-a therapy. Interestingly, a recent study showed that intrahepatic NK cells exhibit reduced cytotoxicity and TRAIL expression in patients with chronic HCV infection when compared to the levels in patients undergoing surgery for an uncomplicated gallstone. ${ }^{11}$ This finding suggests that peripheral NK cells are activated, whereas intrahepatic NK cells may be suppressed, in patients with chronic $\mathrm{HCV}$ infection. The suppression of intrahepatic NK cell functions may be due to either cell-to-cell contact with HCV-infected hepatocytes ${ }^{60}$ or TGF- $\beta$ production from $\mathrm{HCV}$ protein-stimulated monocytes. ${ }^{45}$ Further studies are required to clarify the functions of intrahepatic NK cells during chronic HCV infection.

\section{HBV}

In contrast to HCV infection, the early stages of acute HBV infection are associated with the upregulation of IL-10 in the absence of IFN- $\alpha / \beta$ and IL-15 induction. This production of IL-10 may contribute to the inhibition of peripheral NK cell functions in these patients. ${ }^{40}$ However, a chronic HBV infection with liver inflammation and flares is associated with the activation of peripheral and intrahepatic NK cells, which is likely induced by IFN- $\alpha$, IL-12, IL-15, and IL-18. ${ }^{40},{ }^{44}$ Activated NK cells express high levels of TRAIL and contribute to hepatocellular damage and inflammation in patients with chronic HBV infection; on the other hand, whether activated NK cells also contribute to the control of HBV replication remains unclear. ${ }^{40}, 44$

\section{Alcoholic liver disease (ALD) and non-alcoholic fatty liver disease (NAFLD)}

Alcohol consumption may increase NK cell cytotoxic activity in individuals without ALD, which may contribute to the development of alcoholic liver injury. ${ }^{61}$ However, patients with ALD are always associated with decreased NK cell numbers and a reduced cytotoxic activity. ${ }^{61}$ The suppressed NK cell functions may result in a decrease in the anti-viral, antifibrotic, and anti-tumor effects of NK cells, thereby contributing to an increased susceptibility to viral hepatitis and an accelerated progression of liver fibrosis and hepatocellular carcinoma in ALD patients.

The functions of NKT cells in NAFLD have been extensively investigated. ${ }^{62}$ On the contrary, the involvement of NK cells in this disease remains unclear. It has been reported that obese patients had significantly fewer circulating NK cells than healthy controls, as well as a lower level of cytotoxicity. ${ }^{63}$ However, another study reported that the hepatic NK cell number and expression of NK cell-associated cytotoxic mediators (such as TRAIL, NKG2D, 
and MICA/B mRNAs) in the liver were markedly elevated in obese patients with nonalcoholic steatohepatitis (NASH), and to a lesser extent, in those with nonalcoholic fatty liver when compared to normal healthy control livers. ${ }^{38}$ The expression of MICA/B mRNAs positively correlates with the NAFLD activity score and hepatocyte apoptosis in NASH patients. ${ }^{38}$ This association suggests that NK cells are activated and contribute to the pathogenesis of NASH. The activation of hepatic NK cells during NASH may be due to the elevated levels of several NK cell-activating cytokines (e.g., IL-12, IL-18, and IFN- $\gamma)^{64}$ and ligands (e.g., MICA/B) in these patients. ${ }^{38}$ Further studies are required to clarify the roles of NK cells during NASH, which may help to identify novel therapeutic targets for the treatment of this disease.

\section{Fibrosis and cirrhosis}

NK cell killing of activated HSCs was first demonstrated by two different groups using mouse models in 2006, which play an important role in inhibiting liver fibrosis $;{ }^{8},{ }^{9}$ these results were later confirmed in other mouse models of liver fibrosis. ${ }^{7},{ }^{65},{ }^{66}$ The important anti-fibrotic functions of NK cells were also recently demonstrated in $\mathrm{HCV}$ patients by several clinical studies. ${ }^{5}{ }^{7}$ First, the in vitro co-culture of activated primary human HSCs with human NK cells resulted in the killing of the HSCs via the production of TRAIL and FasL. Second, both the NKG2D and NKp46 activating receptors contributed to the activation of the NK cell-mediated killing of human HSCs. Third, treatment of HCV patients with IFN- $a$ increased the ability of their NK cells to kill primary human HSCs. Fourth, the cytotoxicity against primary human HSCs of NK cells isolated from HCV patients was inversely correlated with their stage of liver fibrosis. Fifth, HCV patient lymphocytes that were transfected with specific inhibitory KIR small interfering RNAs (siRNAs) had increased ability to inhibit human HSC activation. ${ }^{65}$ Finally, the accumulation of NKp46high NK cells in the liver was inversely correlated with the fibrosis stage of HCV patients. Collectively, these findings suggest that NK cells likely play an important role in alleviating liver fibrogenesis. However, the anti-fibrotic function of NK cells can be suppressed by chronic alcohol consumption ${ }^{12}$ and the elevated levels of TGF- $\beta$ that are associated with end-stage liver fibrosis, ${ }^{35}$ which contribute to the progression of liver fibrogenesis.

\section{Autoimmune liver disease}

The dysregulation of NK cell functions is associated with several types of human autoimmune liver disease, including autoimmune hepatitis, primary sclerosing cholangitis, and primary biliary cirrhosis (PBC); NK cells play dual roles in the pathogenesis of these disorders. ${ }^{67},{ }^{68}$ Activated NK cells may promote the progression of PBC by killing biliary epithelial cells via a TRAIL-dependent mechanism and by producing cytokines that enhance the functions of antigen-presenting cells and promote adaptive immunity. ${ }^{69}$ In contrast, NK cells may also diminish PBC progression by inhibiting adaptive immune responses via the production of IL-10 and the killing of autologous DCs and T cells. ${ }^{70}$

\section{Liver cancer}

Hepatic NK cells are enriched in the lymphocytes of a healthy liver, and these cells are constitutively activated. The augmented cytolytic activity of NK cells in the liver, compared to other organs, is critical in the immune surveillance of liver tumors. ${ }^{71}$ The important roles of hepatic NK cells in the immune surveillance for tumors is likely mediated via the production of perforin, granzyme, TRAIL, and IFN $-\gamma .{ }^{2}$ However, the tumor surveillance functions of NK cells are often suppressed in precancerous fibrotic and cirrhotic as well as cancerous tumor-containing livers. For example, a significant reduction in peripheral CD56 ${ }^{\mathrm{dim}}$ NK subsets was found in HCC patients compared with healthy subjects. A dramatic reduction of CD56 ${ }^{\mathrm{dim}} \mathrm{NK}$ subsets was also found in tumor regions compared with non-tumor regions in these HCC patients. ${ }^{72}$ These tumor-infiltrating CD56 ${ }^{\text {dim }}$ NK cells also 
exhibited reduced levels of IFN- $\gamma$ production and cytotoxicity. ${ }^{72}$ But whether the decreased CD56 ${ }^{\mathrm{dim}} \mathrm{NK}$ cells correlated with the poor prognosis in these patients has not been investigated, ${ }^{72}$ although a high density of total intratumoral CD56 ${ }^{+} \mathrm{NK}$ cells has been shown to correlate with long survival rates in HCC patients. ${ }^{73}$ Finally, multiple mechanisms have been suggested to explain the decrease in the NK cell functions that are associated with cirrhosis and liver cancer. These include a fibrosis-mediated inhibition of NK cells, ${ }^{74}$ phagoctyosis of NK cells by $\mathrm{HSC},{ }^{75}$ and the dysregulation of NK cell-activating ligands. ${ }^{76}$

\section{Other liver disorders}

Biliary atresia is a progressive fibro-obliterative cholangiopathy of unclear etiology that affects the biliary trees of infants to various degrees and subsequently disrupts bile flow from the liver to the intestine. The results from experimental models suggest that NK cells are key initiators of cholangiocyte injury by killing cholangiocytes in a contact- and NKG2D-dependent manner. ${ }^{39}$ The uncontrolled NK cell activation found in biliary atresia is likely caused by the postnatal absence of T regulatory cells, which allows for hepatic DCs to act unopposed in NK cell activation. ${ }^{34}, 77$

\section{NK cells as therapeutic targets for the treatment of liver disease}

In summary, NK cells play important roles in inhibiting viral hepatitis, liver fibrosis, and hepatocarcinogenesis. These functions suggest that the activation of NK cells may be a novel therapeutic strategy for the treatment of these liver disorders. Indeed, IFN- $a$, which is one of the most potent NK cell activators, has been widely used to treat viral hepatitis and has also been shown to suppress liver fibrosis and tumor formation. These anti-viral, antifibrotic, and anti-tumor effects of IFN-a therapy are likely mediated, at least in part, via the activation of NK cells. Other NK cell activators, such as IL-12 and IL-18, have been shown to effectively inhibit liver carcinogenesis in animal models. ${ }^{50},{ }^{78}$ In addition, the stimulation of NK cells has been used to enhance NK cell antibody-dependent cell-mediated cytotoxicity (ADCC) against tumor cells and has been tested for the treatment of various types of cancers. ${ }^{79}$ The blockade of NK cell inhibitory receptors is another way to augment NK cytotoxicity against tumor cells. For example, antibodies that block KIR are currently being tested for the potential treatment of hematological cancers in a Phase II clinical trial. ${ }^{80}$ Thus, the activation of NK cells by cytokines, the targeting of NK cells to enhance ADCC, and the blockade of NK cell inhibitory receptors all have therapeutic potential for the treatment of HCC. Finally, feasibility and safety of the adoptive transfer of activated NK cells extracted from cadaveric donor liver graft perfusate for liver transplant recipients with $\mathrm{HCC}$ are currently under investigation in phase I clinical trial (www.clinicaltrials.gov NCT01147380).

\section{Conclusions}

Accumulating evidence from the last two decades suggests that NK cells not only have beneficial effects in inhibiting viral hepatitis, liver fibrosis, and carcinogenesis in the liver but also contribute to hepatocellular damage. Although these findings have significantly enhanced our understanding of liver disease pathogenesis and treatments, further studies are required to clarify the multiple functions of NK cells and translate these findings into clinical practice and therapy.

\section{Acknowledgments}

We wish to apologize to the colleagues whose work was not mentioned or cited in this paper due to space constraints. 


\section{Funding support}

The work described from Dr. Zhigang Tian's lab was supported by the Chinese Natural Science Foundation (91029303, 30911120480, 31021061), the Ministry of Science \& Technology (973-2012CB519004), and the National Science \& Technology Major Projects (2012ZX10002006), and the work described from Dr. Bin Gao's lab was supported by the intramural program of NIAAA, NIH.

\section{Abbreviations}

ADCC antibody-dependent cellular cytotoxicity

ALD alcoholic liver disease

CCL chemokine (C-C motif) ligand

CXCL chemokine (C-X-C motif) ligand

CXCR C-X-C chemokine receptor

DCs dendritic cells

HBV hepatitis B virus

HCC human hepatocellular carcinoma

HCV hepatitis $\mathrm{C}$ virus

HSCs hepatic stellate cells

IFN interferon

IL interleukin

LPS lipopolysaccharide

NAFLD non-alcoholic fatty liver disease

MHC-I major histocompatibility complex class I

MICA MHC class I-related chain A

MIP macrophage inflammatory protein

NK natural killer

NKG2D NK cell group 2D

NKT natural killer T

Treg regulatory $\mathrm{T}$ cell

Poly I:C polyinosinic-polycytidylic acid

Rae-1 retinoic acid early transcript 1

TGF transforming growth factor

TNF tumor necrosis factor

TLR toll like receptor

TRAIL TNF related apoptosis inducing ligand

\section{References}

1. Ishiyama K, Ohdan H, Ohira M, Mitsuta H, Arihiro K, Asahara T. Difference in cytotoxicity against hepatocellular carcinoma between liver and periphery natural killer cells in humans. Hepatology. 2006; 43:362-372. [PubMed: 16440347] 
2. Vermijlen D, Luo D, Froelich CJ, Medema JP, Kummer JA, Willems E, et al. Hepatic natural killer cells exclusively kill splenic/blood natural killer-resistant tumor cells by the perforin/granzyme pathway. J Leukoc Biol. 2002; 72:668-776. [PubMed: 12377935]

3. Ahlenstiel G, Titerence RH, Koh C, Edlich B, Feld JJ, Rotman Y, et al. Natural killer cells are polarized toward cytotoxicity in chronic hepatitis $\mathrm{C}$ in an interferon-alfa-dependent manner. Gastroenterology. 2010; 138:325-335. e3-2. [PubMed: 19747917]

4. Ahlenstiel G, Edlich B, Hogdal LJ, Rotman Y, Noureddin M, Feld JJ, et al. Early changes in natural killer cell function indicate virologic response to interferon therapy for hepatitis $\mathrm{C}$. Gastroenterology. 2011; 141:1231-1239. 1239 e1-2. [PubMed: 21741920]

5. Krämer BKC, Kebschull M, Glässner A, Eisenhardt M, Nischalke HD, Alexander M, Sauerbruch T, Spengler U, Nattermann J. NKp46(High) expression defines a NK cell subset that is potentially involved in control of HCV replication and modulation of liver fibrosis. Hepatology. 2012 in press.

6. Glassner A, Eisenhardt M, Kramer B, Korner C, Coenen M, Sauerbruch T, et al. NK cells from $\mathrm{HCV}$-infected patients effectively induce apoptosis of activated primary human hepatic stellate cells in a TRAIL-, FasL- and NKG2D-dependent manner. Lab Invest. 2012; 92:967-977. [PubMed: 22449797]

7. Gur C, Doron S, Kfir-Erenfeld S, Horwitz E, Abu-Tair L, Safadi R, et al. NKp46-mediated killing of human and mouse hepatic stellate cells attenuates liver fibrosis. Gut. 2012; 61:885-893. [PubMed: 22198715]

8. Radaeva S, Sun R, Jaruga B, Nguyen VT, Tian Z, Gao B. Natural killer cells ameliorate liver fibrosis by killing activated stellate cells in NKG2D-dependent and tumor necrosis factor-related apoptosis-inducing ligand-dependent manners. Gastroenterology. 2006; 130:435-452. [PubMed: 16472598]

9. Melhem A, Muhanna N, Bishara A, Alvarez CE, Ilan Y, Bishara T, et al. Anti-fibrotic activity of NK cells in experimental liver injury through killing of activated HSC. J Hepatol. 2006; 45:60-71. [PubMed: 16515819]

10. Krizhanovsky V, Yon M, Dickins RA, Hearn S, Simon J, Miething C, et al. Senescence of activated stellate cells limits liver fibrosis. Cell. 2008; 134:657-667. [PubMed: 18724938]

11. Varchetta S, Mele D, Mantovani S, Oliviero B, Cremonesi E, Ludovisi S, et al. Impaired intrahepatic natural killer cell cytotoxic function in chronic hepatitis $\mathrm{C}$ virus infection. Hepatology. 2012; 56:841-849. [PubMed: 22431186]

12. Jeong WI, Park O, Gao B. Abrogation of the antifibrotic effects of natural killer cells/interferongamma contributes to alcohol acceleration of liver fibrosis. Gastroenterology. 2008; 134:248-258. [PubMed: 18166357]

13. Maghazachi AA. Role of chemokines in the biology of natural killer cells. Curr Top Microbiol Immunol. 2010; 341:37-58. [PubMed: 20369317]

14. Krueger PD, Lassen MG, Qiao H, Hahn YS. Regulation of NK cell repertoire and function in the liver. Crit Rev Immunol. 2011; 31:43-52. [PubMed: 21395510]

15. Gao B, Radaeva S, Park O. Liver natural killer and natural killer T cells: immunobiology and emerging roles in liver diseases. J Leukoc Biol. 2009; 86:513-528. [PubMed: 19542050]

16. Tu Z, Bozorgzadeh A, Crispe IN, Orloff MS. The activation state of human intrahepatic lymphocytes. Clin Exp Immunol. 2007; 149:186-193. [PubMed: 17511774]

17. Norris S, Collins C, Doherty DG, Smith F, McEntee G, Traynor O, et al. Resident human hepatic lymphocytes are phenotypically different from circulating lymphocytes. J Hepatol. 1998; 28:8490. [PubMed: 9537869]

18. Anfossi N, Andre P, Guia S, Falk CS, Roetynck S, Stewart CA, et al. Human NK cell education by inhibitory receptors for MHC class I. Immunity. 2006; 25:331-342. [PubMed: 16901727]

19. Moroso V, Metselaar HJ, Mancham S, Tilanus HW, Eissens D, van der Meer A, et al. Liver grafts contain a unique subset of natural killer cells that are transferred into the recipient after liver transplantation. Liver Transpl. 2010; 16:895-908. [PubMed: 20583081]

20. Vossen MT, Matmati M, Hertoghs KM, Baars PA, Gent MR, Leclercq G, et al. CD27 defines phenotypically and functionally different human NK cell subsets. J Immunol. 2008; 180:37393745. [PubMed: 18322179] 
21. Li F, Zhu H, Sun R, Wei H, Tian Z. Natural killer cells are involved in acute lung immune injury caused by respiratory syncytial virus infection. J Virol. 2012; 86:2251-2258. [PubMed: 22171263]

22. Hata K, Zhang XR, Iwatsuki S, Van Thiel DH, Herberman RB, Whiteside TL. Isolation, phenotyping, and functional analysis of lymphocytes from human liver. Clin Immunol Immunopathol. 1990; 56:401-419. [PubMed: 1697226]

23. Cooper MA, Fehniger TA, Caligiuri MA. The biology of human natural killer-cell subsets. Trends Immunol. 2001; 22:633-640. [PubMed: 11698225]

24. Lassen MG, Lukens JR, Dolina JS, Brown MG, Hahn YS. Intrahepatic IL-10 maintains NKG2A +Ly49-liver NK cells in a functionally hyporesponsive state. J Immunol. 2010; 184:2693-2701. [PubMed: 20124099]

25. Huntington ND, Vosshenrich CA, Di Santo JP. Developmental pathways that generate naturalkiller-cell diversity in mice and humans. Nat Rev Immunol. 2007; 7:703-714. [PubMed: 17717540]

26. Raulet DH. Roles of the NKG2D immunoreceptor and its ligands. Nat Rev Immunol. 2003; 3:781790. [PubMed: 14523385]

27. Lanier LL. NK cell recognition. Annu Rev Immunol. 2005; 23:225-274. [PubMed: 15771571]

28. Gao B. NKG2D, its ligands, and liver disease - good or bad? Hepatology. 2010; 51:8-11. [PubMed: 20034045]

29. Tu Z, Bozorgzadeh A, Pierce RH, Kurtis J, Crispe IN, Orloff MS. TLR-dependent cross talk between human Kupffer cells and NK cells. J Exp Med. 2008; 205:233-244. [PubMed: 18195076]

30. Dong Z, Wei H, Sun R, Hu Z, Gao B, Tian Z. Involvement of natural killer cells in PolyI:Cinduced liver injury. J Hepatol. 2004; 41:966-973. [PubMed: 15582130]

31. Hou X, Zhou R, Wei H, Sun R, Tian Z. NKG2D-retinoic acid early inducible-1 recognition between natural killer cells and Kupffer cells in a novel murine natural killer cell-dependent fulminant hepatitis. Hepatology. 2009; 49:940-949. [PubMed: 19177594]

32. Chen Y, Wei H, Sun R, Dong Z, Zhang J, Tian Z. Increased susceptibility to liver injury in hepatitis B virus transgenic mice involves NKG2D-ligand interaction and natural killer cells. Hepatology. 2007; 46:706-715. [PubMed: 17626270]

33. Okazaki A, Hiraga N, Imamura M, Hayes CN, Tsuge M, Takahashi S, et al. Severe necroinflammatory reaction caused by natural killer cell-mediated Fas/Fas ligand interaction and dendritic cells in human hepatocyte chimeric mouse. Hepatology. 2012; 56:555-566. [PubMed: 22331638]

34. Miethke AG, Saxena V, Shivakumar P, Sabla GE, Simmons J, Chougnet CA. Post-natal paucity of regulatory $\mathrm{T}$ cells and control of $\mathrm{NK}$ cell activation in experimental biliary atresia. J Hepatol. 2010; 52:718-726. [PubMed: 20347178]

35. Jeong WI, Park O, Suh YG, Byun JS, Park SY, Choi E, et al. Suppression of innate immunity (natural killer cell/interferon-gamma) in the advanced stages of liver fibrosis in mice. Hepatology. 2011; 53:1342-1351. [PubMed: 21480338]

36. Cheng CW, Duwaerts CC, Rooijen N, Wintermeyer P, Mott S, Gregory SH. NK cells suppress experimental cholestatic liver injury by an interleukin-6-mediated, Kupffer cell-dependent mechanism. J Hepatol. 2011; 54:746-752. [PubMed: 21129806]

37. Wang J, Sun R, Wei H, Dong Z, Gao B, Tian Z. Poly I:C prevents T cell-mediated hepatitis via an NK-dependent mechanism. J Hepatol. 2006; 44:446-454. [PubMed: 16310275]

38. Kahraman A, Schlattjan M, Kocabayoglu P, Yildiz-Meziletoglu S, Schlensak M, Fingas CD, et al. Major histocompatibility complex class I-related chains A and B (MIC A/B): a novel role in nonalcoholic steatohepatitis. Hepatology. 2010; 51:92-102. [PubMed: 19998387]

39. Shivakumar P, Sabla GE, Whitington P, Chougnet CA, Bezerra JA. Neonatal NK cells target the mouse duct epithelium via $\mathrm{Nkg} 2 \mathrm{~d}$ and drive tissue-specific injury in experimental biliary atresia. $\mathrm{J}$ Clin Invest. 2009; 119:2281-2290. [PubMed: 19662681]

40. Dunn C, Brunetto M, Reynolds G, Christophides T, Kennedy PT, Lampertico P, et al. Cytokines induced during chronic hepatitis B virus infection promote a pathway for NK cell-mediated liver damage. J Exp Med. 2007; 204:667-680. [PubMed: 17353365] 
41. Stegmann KA, Bjorkstrom NK, Veber H, Ciesek S, Riese P, Wiegand J, et al. Interferon-alphainduced TRAIL on natural killer cells is associated with control of hepatitis $\mathrm{C}$ virus infection. Gastroenterology. 2010; 138:1885-1897. [PubMed: 20334827]

42. Ochi M, Ohdan H, Mitsuta H, Onoe T, Tokita D, Hara H, et al. Liver NK cells expressing TRAIL are toxic against self hepatocytes in mice. Hepatology. 2004; 39:1321-1331. [PubMed: 15122761]

43. Zou Y, Chen T, Han M, Wang H, Yan W, Song G, et al. Increased killing of liver NK cells by Fas/ Fas ligand and NKG2D/NKG2D ligand contributes to hepatocyte necrosis in virus-induced liver failure. J Immunol. 2010; 184:466-475. [PubMed: 19949088]

44. Zhang Z, Zhang S, Zou Z, Shi J, Zhao J, Fan R, et al. Hypercytolytic activity of hepatic natural killer cells correlates with liver injury in chronic hepatitis B patients. Hepatology. 2011; 53:73-85. [PubMed: 21254163]

45. Sene D, Levasseur F, Abel M, Lambert M, Camous X, Hernandez C, et al. Hepatitis C virus (HCV) evades NKG2D-dependent NK cell responses through NS5A-mediated imbalance of inflammatory cytokines. PLoS Pathog. 2010; 6:e1001184. [PubMed: 21085608]

46. Sun C, Fu B, Gao Y, Liao X, Sun R, Tian Z, et al. TGF-beta1 down-regulation of NKG2D/DAP10 and 2B4/SAP expression on human NK cells contributes to HBV persistence. PLoS Pathog. 2012; 8:e1002594. [PubMed: 22438812]

47. Peppa D, Micco L, Javaid A, Kennedy PT, Schurich A, Dunn C, et al. Blockade of immunosuppressive cytokines restores NK cell antiviral function in chronic hepatitis B virus infection. PLoS Pathog. 2010; 6:e1001227. [PubMed: 21187913]

48. Wang SH, Huang CX, Ye L, Wang X, Song L, Wang YJ, et al. Natural killer cells suppress full cycle HCV infection of human hepatocytes. J Viral Hepat. 2008; 15:855-864. [PubMed: 18637071]

49. Sun R, Gao B. Negative regulation of liver regeneration by innate immunity (natural killer cells/ interferon-gamma). Gastroenterology. 2004; 127:1525-1539. [PubMed: 15521020]

50. Subleski JJ, Hall VL, Back TC, Ortaldo JR, Wiltrout RH. Enhanced antitumor response by divergent modulation of natural killer and natural killer T cells in the liver. Cancer Res. 2006; 66:11005-11012. [PubMed: 17108139]

51. Khakoo SI, Thio CL, Martin MP, Brooks CR, Gao X, Astemborski J, et al. HLA and NK cell inhibitory receptor genes in resolving hepatitis C virus infection. Science. 2004; 305:872-874. [PubMed: 15297676]

52. Cheent K, Khakoo SI. Natural killer cells and hepatitis C: action and reaction. Gut. 2011; 60:268278. [PubMed: 20876777]

53. Shoukry NH, Pelletier S, Chang KM. A view to natural killer cells in hepatitis C. Gastroenterology. 2011; 141:1144-1148. [PubMed: 21875586]

54. Amadei B, Urbani S, Cazaly A, Fisicaro P, Zerbini A, Ahmed P, et al. Activation of natural killer cells during acute infection with hepatitis $C$ virus. Gastroenterology. 2010; 138:1536-1545. [PubMed: 20080094]

55. Pelletier S, Drouin C, Bedard N, Khakoo SI, Bruneau J, Shoukry NH. Increased degranulation of natural killer cells during acute $\mathrm{HCV}$ correlates with the magnitude of virus-specific T cell responses. J Hepatol. 2010; 53:805-816. [PubMed: 20688412]

56. Golden-Mason L, Cox AL, Randall JA, Cheng L, Rosen HR. Increased natural killer cell cytotoxicity and $\mathrm{NKp} 30$ expression protects against hepatitis $\mathrm{C}$ virus infection in high-risk individuals and inhibits replication in vitro. Hepatology. 2010; 52:1581-1589. [PubMed: 20812318]

57. Oliviero B, Varchetta S, Paudice E, Michelone G, Zaramella M, Mavilio D, et al. Natural killer cell functional dichotomy in chronic hepatitis $\mathrm{B}$ and chronic hepatitis $\mathrm{C}$ virus infections. Gastroenterology. 2009; 137:1151-1160. [PubMed: 19470388]

58. Golden-Mason LSA, Bambha KM, Cheng L, Rosen HR. Race- and gender-related variation in NKp46 expression associated with differential anti-HCV immunity. Hepatlogy. 2012:25771.

59. Edlich B, Ahlenstiel G, Azpiroz AZ, Stoltzfus J, Noureddin M, Serti E, et al. Early changes in interferon signaling define natural killer cell response and refractoriness to interferon-based therapy of hepatitis C patients. Hepatology. 2012; 55:39-48. [PubMed: 21898483] 
60. Yoon JC, Lim JB, Park JH, Lee JM. Cell-to-cell contact with hepatitis C virus-infected cells reduces functional capacity of natural killer cells. J Virol. 2011; 85:12557-12569. [PubMed: 21937646]

61. Laso FJ, Almeida J, Torres E, Vaquero JM, Marcos M, Orfao A. Chronic alcohol consumption is associated with an increased cytotoxic profile of circulating lymphocytes that may be related with the development of liver injury. Alcohol Clin Exp Res. 2010; 34:876-885. [PubMed: 20201930]

62. Syn WK, Oo YH, Pereira TA, Karaca GF, Jung Y, Omenetti A, et al. Accumulation of natural killer T cells in progressive nonalcoholic fatty liver disease. Hepatology. 2010; 51:1998-2007. [PubMed: 20512988]

63. O'Shea D, Cawood TJ, O'Farrelly C, Lynch L. Natural killer cells in obesity: impaired function and increased susceptibility to the effects of cigarette smoke. PLoS One. 2010; 5:e8660. [PubMed: 20107494]

64. Bertola A, Bonnafous S, Anty R, Patouraux S, Saint-Paul MC, Iannelli A, et al. Hepatic expression patterns of inflammatory and immune response genes associated with obesity and NASH in morbidly obese patients. PLoS One. 2010; 5:e13577. [PubMed: 21042596]

65. Muhanna N, Abu Tair L, Doron S, Amer J, Azzeh M, Mahamid M, et al. Amelioration of hepatic fibrosis by NK cell activation. Gut. 2011; 60:90-98. [PubMed: 20660699]

66. Hou X, Yu F, Man S, Huang D, Zhang Y, Liu M, et al. Negative regulation of Schistosoma japonicum egg-induced liver fibrosis by natural killer cells. PLoS Negl Trop Dis. 2012; 6:e1456. [PubMed: 22235358]

67. Tian Z, Gershwin ME, Zhang C. Regulatory NK cells in autoimmune disease. J Autoimmun. 2012; 39:206-215. [PubMed: 22704425]

68. Gao B, Bertola A. Natural killer cells take two tolls to destruct bile ducts. Hepatology. 2011; 53:1076-1079. [PubMed: 21384404]

69. Shimoda S, Harada K, Niiro H, Shirabe K, Taketomi A, Maehara Y, et al. Interaction between Toll-like receptors and natural killer cells in the destruction of bile ducts in primary biliary cirrhosis. Hepatology. 2011; 53:1270-1281. [PubMed: 21400555]

70. Schleinitz N, Vely F, Harle JR, Vivier E. Natural killer cells in human autoimmune diseases. Immunology. 2010; 131:451-458. [PubMed: 21039469]

71. Subleski JJ, Wiltrout RH, Weiss JM. Application of tissue-specific NK and NKT cell activity for tumor immunotherapy. J Autoimmun. 2009; 33:275-281. [PubMed: 19682859]

72. Cai L, Zhang Z, Zhou L, Wang H, Fu J, Zhang S, et al. Functional impairment in circulating and intrahepatic NK cells and relative mechanism in hepatocellular carcinoma patients. Clin Immunol. 2008; 129:428-437. [PubMed: 18824414]

73. Chew V, Chen J, Lee D, Loh E, Lee J, Lim KH, et al. Chemokine-driven lymphocyte infiltration: an early intratumoural event determining long-term survival in resectable hepatocellular carcinoma. Gut. 2012; 61:427-438. [PubMed: 21930732]

74. Zhang DY, Friedman SL. Fibrosis-dependent mechanisms of hepatocarcinogenesis. Hepatology. 2012; 56:769-775. [PubMed: 22378017]

75. Muhanna N, Doron S, Wald O, Horani A, Eid A, Pappo O, et al. Activation of hepatic stellate cells after phagocytosis of lymphocytes: A novel pathway of fibrogenesis. Hepatology. 2008; 48:963977. [PubMed: 18726940]

76. Coulouarn C, Factor VM, Conner EA, Thorgeirsson SS. Genomic modeling of tumor onset and progression in a mouse model of aggressive human liver cancer. Carcinogenesis. 2011; 32:14341440. [PubMed: 21771728]

77. Saxena V, Shivakumar P, Sabla G, Mourya R, Chougnet C, Bezerra JA. Dendritic cells regulate natural killer cell activation and epithelial injury in experimental biliary atresia. Sci Transl Med. 2011; 3:102ra94.

78. Chang CJ, Chen YH, Huang KW, Cheng HW, Chan SF, Tai KF, et al. Combined GM-CSF and IL-12 gene therapy synergistically suppresses the growth of orthotopic liver tumors. Hepatology. 2007; 45:746-754. [PubMed: 17326190]

79. Houot R, Kohrt HE, Marabelle A, Levy R. Targeting immune effector cells to promote antibodyinduced cytotoxicity in cancer immunotherapy. Trends Immunol. 2011; 32:510-516. [PubMed: 21907000] 
80. Alici E. IPH-2101, a fully human anti-NK-cell inhibitory receptor mAb for the potential treatment of hematological cancers. Curr Opin Mol Ther. 2010; 12:724-733. [PubMed: 21154164] 


\section{Human liver}

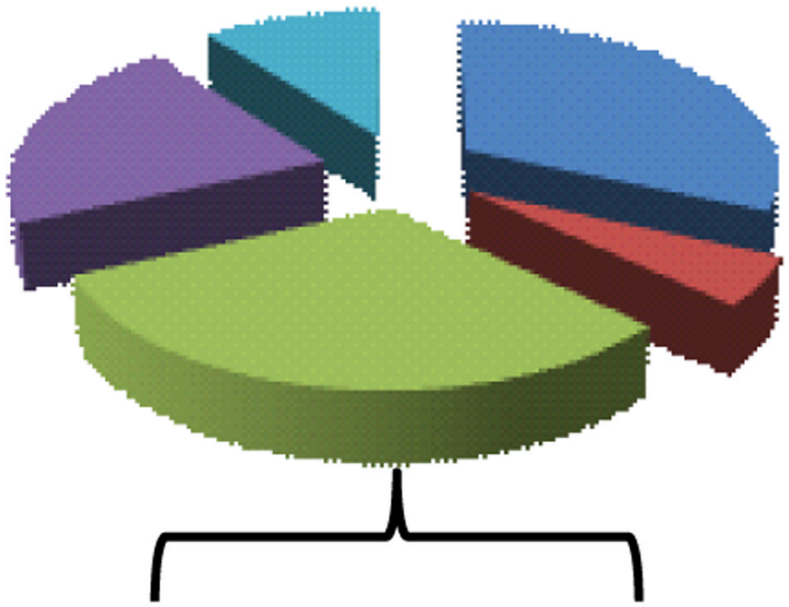

\section{$\alpha \beta$ T cells}

B cell

NK cell
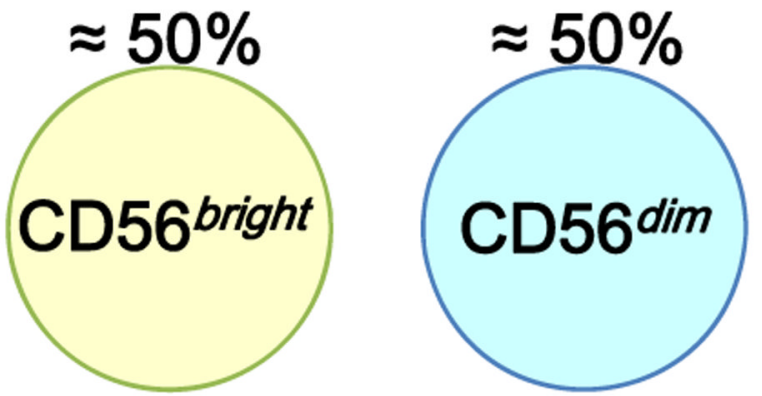

$\gamma \delta \mathrm{T}$ cell

CD16-

CD69+/-

CCR7+

CXCR3+

MIP-1 $\alpha / \beta+$

TRAIL+

\section{ADCC-}

Figure 1. Intrahepatic NK cells in humans

The cell composition of lymphocytes in the human liver is shown. Human liver NK cells include the CD56 ${ }^{\text {bright }}$ and CD56 ${ }^{\text {dim }}$ subsets. The two subsets exhibit significant differences in their proliferative responses to IL-2, intrinsic cytotoxic capacity, cytokine production, NKR repertoire, and adhesion molecule expression. (1) CD56 $6^{\text {bright }} \mathrm{NK}$ cells expand in response to low doses of IL-2, whereas CD56 ${ }^{\text {dim }} \mathrm{NK}$ cells respond poorly to IL-2

stimulation. (2) CD56 ${ }^{\text {bright }} \mathrm{NK}$ cells have a high level of expression of the CD94/ NKG2 Ctype lectin receptors and less than $10 \%$ of them express KIR. In contrast, more than $85 \%$ of

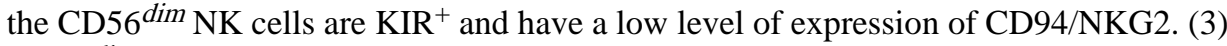
$\mathrm{CD} 6^{\mathrm{dim}} \mathrm{NK}$ cells are more cytotoxic against NK-sensitive targets but produce lower 
amounts of cytokines than CD56 ${ }^{\text {bright }} \mathrm{NK}$ cells. (4) CD56 ${ }^{\text {bright }} \mathrm{NK}$ cells express high levels of CCR7 and CXCR3. (5) Finally, CD56 ${ }^{\text {bright }}$ NK cells can be induced from NK cell precursors by IL-15 and may then differentiate into CD $56^{\text {dim }} \mathrm{NK}$ cells. 


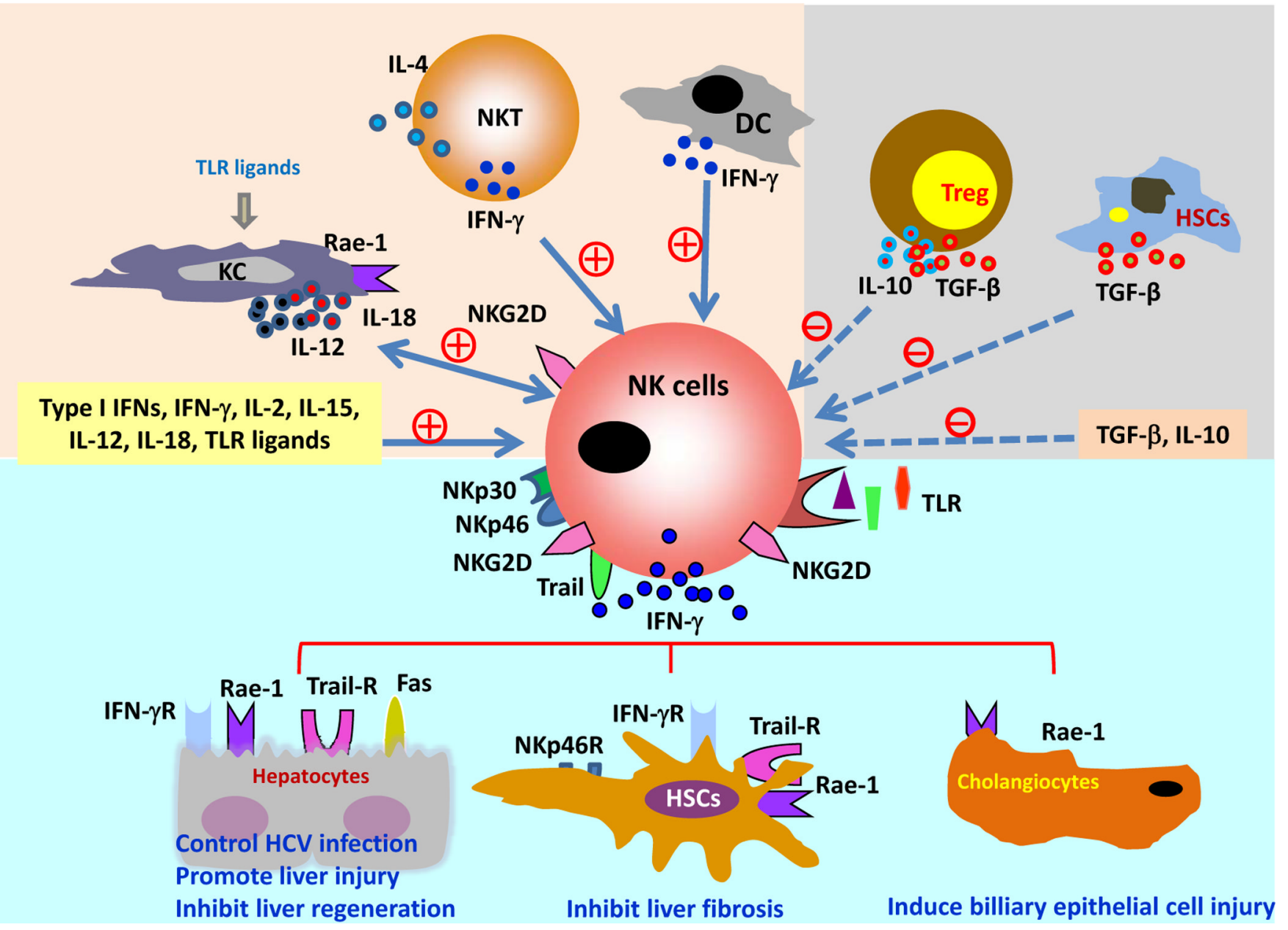

Figure 2. The regulation and functions of liver NK cells. Top panel: The regulation of NK cells The left side of the top panel illustrates that activated Kupffer cells (KCs), dendritic cells (DCs), and NKT cells can induce NK cell activation via the production of a variety of cytokines. Several cytokines that activate NK cells are also listed. The right side of the top panel illustrates that T regulatory cells and activated HSCs can inhibit NK cell functions via the production of several cytokines. TGF- $\beta$ is a potent inhibitor of NK cell functions.

Bottom panel: The functions of $\mathrm{NK}$ cells in the liver. Activated NK cells target hepatocytes, HSCs, and cholangiocytes and perform a variety of important functions in the pathogenesis of liver disease. 


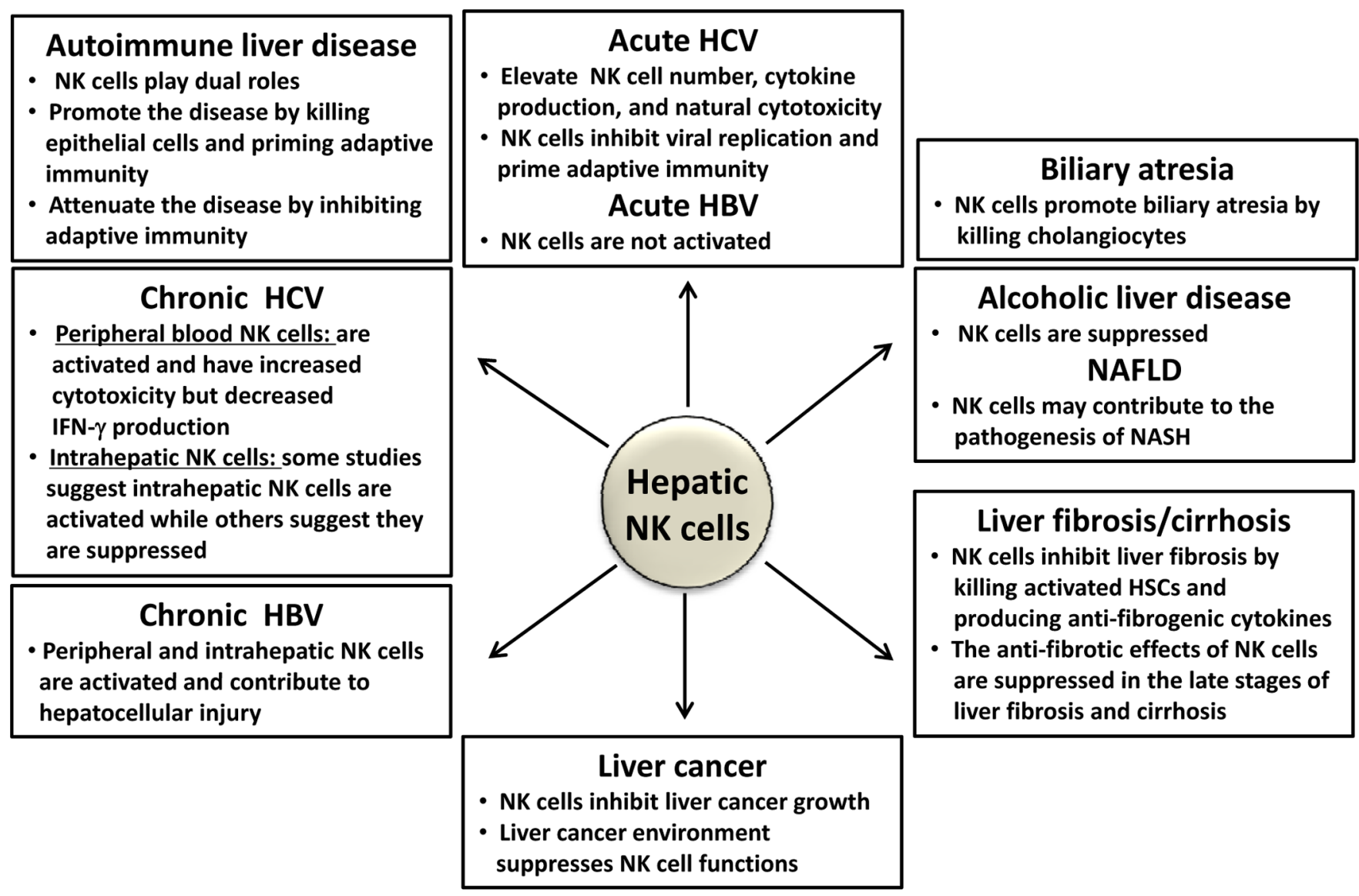

Figure 3. The roles of hepatic NK cells in human liver diseases In a variety of liver diseases, such as viral hepatitis, fatty liver, liver fibrosis, cirrhosis, tumor, and others, significant alterations of hepatic NK cells are observed. NK cells can accumulate within the liver and have higher levels of cytotoxicity and cytokine production, which can be beneficial in inhibiting viral infection, tumor cell growth, and liver fibrosis but can also enhance hepatocellular damage. In addition, chronic liver diseases are associated with a decreased number of NK cells and impairments in NK cell cytotoxicity and cytokine production. 
Table I

Differences between human liver and peripheral NK cells

\begin{tabular}{|c|c|c|c|}
\hline & Liver NK cells & Circulating NK cells & References \\
\hline CD3-CD56+ & $30.6 \%(11.6-51.3 \%)$ & $12.8 \%(1-22 \%)$ & 17 \\
\hline CD56 $6^{\text {bright/total NK cell }}$ & $\sim 50 \%$ & $\sim 10 \%$ & 18,19 \\
\hline CD56 ${ }^{\mathrm{dim} / \text { total NK cell }}$ & $\sim 50 \%$ & $\sim 90 \%$ & 18,19 \\
\hline CD27 & high & low & 20,21 \\
\hline CD16 & - & + & 18,22 \\
\hline CD69 & $+/-$, higher & $+1-$ & 16 \\
\hline Chemokine receptor & $\begin{array}{l}\text { CCR7 and CXCR3 } \\
\left.\text { (CD56 } 6^{\text {bright }}\right)\end{array}$ & $\begin{array}{l}\text { CXCR1, CX3CR1 } \\
\text { (CD56 }\end{array}$ & 13,23 \\
\hline Inhibitory receptor (NKG2A) & high & low & 24 \\
\hline Natural cytotoxicity & higher & high & 18,19 \\
\hline TRAIL & high & low & 1 \\
\hline Perforin, Granzyme B & high & low & 2 \\
\hline Cytokine production & $\begin{array}{l}\text { high } \\
\text { (MIP-1a/ } \beta, \text { IL-10, } \\
\text { TNF- } \alpha, \text { TNF- } \beta, \text { IFN- } \gamma \text {, } \\
\text { GM-CSF) }\end{array}$ & $\begin{array}{l}\text { low } \\
\text { (TNF-a, TNF- } \beta, \text { IFN- } \gamma \text {, } \\
\text { GM-CSF, IL-10) }\end{array}$ & 18 \\
\hline $\mathrm{ADCC}$ & - & high & 25 \\
\hline
\end{tabular}

